\title{
PROCESSO COLETIVO DEMOCRÁTICO SOB A ÓTICA DA TEORIA DAS AÇÕES COLETIVAS COMO AÇÕES TEMÁTICAS: UM ESTUDO DA LEGITIMIDADE PROCESSUAL ATIVA DO CIDADÃO PROPOR AÇÃO CIVIL PÚBLICA
}

\author{
Fabrício Veiga Costa ${ }^{1}$ \\ Natielli Efigênia Mucelli Rezende Veloso ${ }^{2}$
}

\begin{abstract}
Resumo: O objetivo da pesquisa é apresentar proposições teóricas que legitimam democraticamente o os interessados difusos e coletivos na construção participada do mérito processual nas ações civis públicas, considerando-se que o legislador, no artigo 5., da Lei 7347/85, exclui os cidadãos do rol dos legitimados ativos à propositura da referida ação coletiva. Por meio da pesquisa bibliográfica e documental demonstrou-se que o modelo de processo coletivo vigente brasileiro se funda no sistema representativo, é autocrático, além de contrariar o sistema participativo, que autoriza constitucionalmente o direito de todos os sujeitos afetados pelo provimento final participar de sua construção.
\end{abstract}

Palavras-chave: Processo coletivo; Ação civil pública; Jurisdição constitucional; Processo constitucional democrático; Legitimidade processual.

\section{DEMOCRATIC COLLECTIVE PROCESS FROM THE THEORY OF THE COLLECTIVE ACTIONS AS THEMATIC ACTIONS: A STUDY OF THE CITIZEN'S ACTIVE PROCESSUAL LEGITIMACY PROPOSAL PUBLIC CIVIL ACTION}

\begin{abstract}
The aim of the research is to present theoretical propositions that democratically legitimize the diffuse and collective stakeholders in the construction of procedural merit in public civil actions, considering that the legislator, in article 5 of Law 7347/85, excludes citizens from legitimized assets to the filing of said collective action. Through bibliographic and documentary research, it has been demonstrated that the Brazilian model of collective action is based on the representative system, is autocratic, and contradicts the participatory system, which constitutionally authorizes the right of all subjects affected by the final provision to participate in its construction.
\end{abstract}

Keywords: Collective process; Public civil action; Constitutional Jurisdiction; Constitutional democratic process; See the full content of this document

\section{Introdução}

A reconstrução do processo coletivo a partir do modelo constitucional de processo é uma necessidade no Estado Democrático de Direito. A superação do modelo de processo

\footnotetext{
${ }^{1}$ Professor do Programa de Pós-graduação Stricto Sensu em Proteção dos Direitos Fundamentais pela Universidade de Itaúna. Doutor em Direito pela Pucminas. Pós-doutorado em Educação pela UFMG. E-mail: fvcufu@ uol.com.br

${ }^{2}$ Mestranda em Proteção dos Direitos Fundamentais pela Universidade de Itaúna. Bacharel em Direito pela UFMG.

E-mail: natielliveloso@gmail.com
} 
coletivo, centrado no sistema representativo, viabiliza o seu entendimento critico mediante a participação de todos aqueles juridicamente interessados na construção do mérito das ações coletivas. Dessa forma busca-se, com a presente pesquisa, apresentar um debate jurídico acerca da problemática e da necessidade de discussão da procedimentalização do processo coletivo desvinculado de acepções autocráticas e individualistas. O advento do direito coletivo como ramo cientificamente autônomo demonstra a necessidade de proposições tendentes à criação de uma Teoria Geral do Processo Coletivo, justamente para alcançar o desvencilhamento com o modelo de processo centrado em pretensões de cunho individual.

Faz-se necessária a sistematização da legislação brasileira esparsa referente aos direitos coletivos, com a finalidade de buscar a construção de um sistema jurídico de proteção das pretensões dos interessados difusos nos moldes democráticos. Reformas processuais pontuais não são suficientes para a ruptura com a acepção instrumentalista de processo, centrada no ideal individualista e liberal. Faz-se necessário repensar o processo constitucional a partir do entendimento de que o devido processo legal, a isonomia processual, a publicidade dos atos processuais, o contraditório e a ampla defesa são corolários indispensáveis à efetivação dos direitos fundamentais garantidos no plano constituinte.

É nesse contexto teórico que se torna necessário pensar o processo coletivo sob à ótica crítica do principio da supremacia da constituição, para, assim, implementar a participação dos interessados no provimento a partir da teoria das ações coletivas como ações temáticas. A democratização do acesso à jurisdição coletiva pelo principio da participação é o fundamento suficiente para superar o entendimento dogmático de uma jurisdição autoridade, centrada no poder do julgador, e assim expor proposições suficientes ao entendimento da jurisdição como um direito fundamental assegurado indistintamente a todos os cidadãos de discutirem pretensões tanto de conotação individual quanto coletiva.

A pergunta-problema proposta, como meio de delimitar o objeto de análise, funda-se na seguinte indagação: o modelo de processo coletivo brasileiro vigente, ao excluir o cidadão do rol dos legitimados ativos à propositura da ação civil pública, observa o modelo constitucional-democrático-participativo de processo?

A hipótese cientifica que conduzirá todo o estudo proposto nessa pesquisa gira em torno da seguinte problemática: o atual modelo de processo coletivo proposto pela Escola Instrumentalista corrobora com o paradigma do Estado Democrático de Direito? Certamente não, uma vez que o fato do direito processual coletivo ser discutido sob o patamar da 
representatividade não é suficiente para viabilizar a participação direta dos interessados difusos e coletivos na construção isonômica do provimento jurisdicional, cujos efeitos da decisão afetarão indistintamente todos aqueles a quem devem ser assegurados o direito de participação no debate de todos os temas correlatos à pretensão inicialmente deduzida.

Através da pesquisa teórico-bibliográfica e documental, foi possível construir análises críticas, temáticas, interpretativas e comparativas, por meio das quais demonstrou-se que o modelo participativo adotado pelo texto da constituição brasileira de 1988 é o referencial teórico hábil a legitimar democraticamente a participação de todos os interessados difusos na construção argumentativa do provimento final. O método dedutivo foi o parâmetro utilizado para a delimitação do objeto da pesquisa, pois partiu-se de uma abordagem ampla, qual seja, o modelo de processo coletivo brasileiro centrado no sistema representativo, recortando-se o debate da participação popular na formação do mérito a partir da teoria das ações coletivas como ações temáticas, privilegiando a jurisdição democrática como direito fundamental.

\section{Historicidade do processo coletivo}

Pensar o processo coletivo sob a égide individualista proposta pela Escola Instrumentalista é certamente admitir a existência de profunda incompatibilidade entre o sistema representativo e o sistema participativo. É a partir dessa premissa que se pretende demonstrar a construção do pensamento do direito e do processo coletivo enquanto disciplinas cientificamente autônomas e dotadas de um objeto próprio.

A proteção dos direitos coletivos, de natureza metaindividual, é uma preocupação que transpassa a historiografia mundial, ou seja, a necessidade de disciplinar juridicamente tais direitos coincide certamente com o advento das civilizações. Nesse ínterim pode-se afirmar que o antecedente histórico mais remoto que se tem noticia no estudo do direito coletivo é a ação popular romana.

O interesse dos romanos para com a proteção jurídica não apenas dos conflitos individuais certamente se explica pela construção do ideal de Democracia prevalente ao longo de toda a história do Império Romano. Tal afirmação se justifica pela solidificação da idéia de interesse público, muito evidente no Direito Romano e produto da construção da res publica que viabilizava o sentimento de cada cidadão romano poder pleitear judicialmente e também 
participar de todas as decisões referentes ao interesse publico. Por isso, resta clara a afirmação de que, embora a base do Direito Romano encontrava-se sedimentada no Direito Privado, o cidadão romano podia participar ativamente da vida do Estado através do instrumento da ação popular, o que não significava a prevalência dos interesses estatais em detrimento dos interesses dos cidadãos (LEONEL, 2002, p. 40-43).

A ação popular romana tinha caráter predominantemente penal e visava, acima de tudo, a defesa de coisas publicas e de caráter sacro. Dentre os legitimados, as mulheres e os menores eram excluídos, por não serem reconhecidos como cidadãos. Ressalta-se, ainda, a impossibilidade de substituição processual em caso de morte do autor da ação, o que demonstrar ser um profundo equivoco, até porque, se o objeto da ação versa sobre uma pretensão metaindividual não se justificava a extinção do processo com a morte do autor da ação. Admitia-se, também, a qualquer tempo, a oposição de exceção à coisa julgada, sempre que demonstrado o interesse democraticamente legitimo de prosseguir com o debate jurídico de novas questões relacionadas a pretensão inicialmente deduzida em juízo e de caráter e interesse da coletividade (LEONEL, 2002, p.44-45).

Resta esclarecer que através da ação popular o cidadão romano podia controlar a atividade estatal, com o propósito de averiguar se o interesse da coletividade estava sendo efetivamente protegido. Tratava-se de um instrumento hábil a controlar não somente a atividade estatal, mas acima de tudo, limitar o exercício abusivo das liberdades individuais que pudessem contrariar os interesses da coletividade. Nesse sentido afirma-se

\begin{abstract}
A ação popular tinha em Roma amplitude extraordinária, servindo não somente para a tutela de interesses individuais com conseqüências publicas (como no caso de defesa pessoal do uso de vias publicas por meio do interdictum ne quid in loco publico vel itinere fiate; como ainda da utilização dos rios, ancoradouros, bebedouros, entre outras coisas, por força dos interdictum ne quid in flumine publico ripave ejus Fiat; uso de esgotos públicos, por meio do interdito de cloacis, entre outros); mas ainda, e sobretudo, para a tutela de interesses mais propriamente coletivos, como na defesa de sepultura comum, efetivação de fundações instituídas por atos de disposicao de ultima vontade, oposição à colocação de telhas e janelas de coisas que pudesses ser lançadas à rua, entre outras (LEONEL, 2002, p. 47).
\end{abstract}

É recente a regulamentação da ação popular, tendo ocorrido em 30 de março de 1836, com a lei comunal, na Bélgica e, em seguida, na França, com a lei comunal de 18 de julho de 1837. Na Itália foram implementadas em 20 de setembro de 1859 a lei 26, que previa a possibilidade de ação popular para matéria eleitoral, e também a Lei 765, de 06 de agosto de 1927, que previa o uso da ação popular em matéria urbanística (LEONEL, 2002, p. 52). 


\section{PROCESSO COLETIVO DEMOCRÁTICO SOB A ÓTICA DA TEORIA DAS AÇÕES COLETIVAS COMO AÇÕES TEMÁTICAS: UM ESTUDO DA LEGITIMIDADE PROCESSUAL ATIVA DO CIDADÃO PROPOR AÇÃO CIVIL PÚBLICA}

No Brasil não foi diferente, uma vez que a gênese do processo coletivo está ação popular, que foi inicialmente inserida no direito pátrio através do artigo 113, inciso XXXVIII da Constituição de 1934: "Qualquer cidadão será parte legítima para pleitear a declaração de nulidade ou anulação de atos lesivos do patrimônio da União, Estados ou dos Municípios" (BRASIL, 2001, p. 161). É de suma importância esclarecer que o primeiro instrumento processual hábil no direito pátrio ao controle das atividades estatais encontra-se na Constituição de 1934, especificamente no que tange ao controle do patrimônio público. Sabese que historicamente tal possibilidade foi suprimida na Constituição de 1937, que pelo próprio contexto histórico, marcado por um regime político de exceção, o cidadão encontravase impossibilitado de participar das decisões estatais e se encontrava refém do arbítrio dos detentores do poder. Assim ressalta-se

No intervalo observado entre a Constituição do Estado Novo até a publicação da Carta de 1946, foi editado o novo ordenamento processual civil unificado, sendo que neste havia a previsão, no artigo 670, da possibilidade de ajuizamento de ação pelo Ministério Público ou por qualquer do povo, com o escopo de dissolver associação civil com personalidade juridica que promovesse atividade ilícita ou imoral, reavivando aquela espécie de ação que já fora prevista anteriormente na própria Carta de 1934, tida pela doutrina de então como popular (LEONEL, 2002, p. 52).

Com o advento da Constituição de 1946 houve o renascimento da ação popular em seu artigo 141, inciso XXXVIII: "Qualquer cidadão será parte legítima para pleitear a anulação ou a declaração de nulidade de atos lesivos ao patrimônio da União, dos Estados, dos Municípios, das entidades autárquicas e das sociedades de economia mista" (BRASIL, 2001, p. 103). Novamente temos a possibilidade jurídica de controle do patrimônio público pelo cidadão. Dessa forma observa-se:

[...] Em seguida, foram instituídas ainda duas ações de natureza popular no âmbito da legislação infraconstitucional, quais sejam: uma pelo artigo 35, $\S 1^{\circ}$, da Lei 818 , de 18.09.1949, relacionada à aquisição, perda e reaquisição da nacionalidade e perda de direitos políticos; e ainda outra, pelo artigo 15, $\S 1^{\circ}$, da Lei 3.052, de 21.12.1958, relativa à impugnação do enriquecimento ilícito (matéria hoje regulada pela Lei 8.429/92, que será tratada oportunamente). [...] (LEONEL, 2002, p. 54).

Em 29 de junho de 1965, em pleno período da ditadura militar, foi sancionada a Lei 4.717, que disciplinava no plano infraconstitucional a ação popular. Reconheceu-se a legitimidade processual de qualquer cidadão pleitear a anulação ou a declaração de nulidade 
de atos lesivos ao patrimônio dos entes da administração pública direta e indireta. O requisito para a comprovação da cidadania e da legitimidade para a propositura da presente ação era o titulo de eleitor e a demonstração da regularidade no exercício dos direitos políticos. A sentença de improcedência ou de carência da ação estava sujeita ao reexame necessário e a de procedência à possibilidade de propositura de recurso de apelação recebido no efeito suspensivo (BRASIL, Vademecum, 2007, p. 1080-1082).

Tal legislação denota a tentativa do legislador institucionalizar o controle das atividades estatais diretamente pelo cidadão. Acontece que tal fiscalidade não era de natureza ampla, excluindo-se, por exemplo, a possibilidade de controle do meio ambiente e demais direitos de natureza metaindividual e potencializador do exercício pleno da cidadania. Com isso, sabe-se que há, nesse período da história brasileira, o início da legitimação do cidadão no controle e fiscalidade das atividades estatais, até porque tal controle era um tanto limitado em decorrência do próprio contexto da historiografia brasileira, um período de regime político de exceção.

A Carta de 1967 (Constituição brasileira de 1967), e a Emenda Constitucional 1/69, em seu artigo 153, inciso XXXI previa: “Qualquer cidadão será parte legítima para propor ação popular que vise a anular atos lesivos ao patrimônio de entidades públicas" (BRASIL, 2001, p.165). Novamente ressalta-se a existência de uma previsão legal um tanto genérica, que garante ao cidadão um controle restrito das atividades estatais e à margem da legitimidade democrática e do modelo constitucional de processo coletivo.

Em 24 de julho de 1985 adveio para o sistema jurídico brasileiro a Lei 7.347, que disciplinou a ação civil pública, cujo objeto pode ser o meio ambiente, o consumidor e patrimônio público. Essa representa mais uma tentativa de o legislador pátrio regulamentar através de uma legislação especifica o processo coletivo. Verifica-se que o tratamento jurídico-legal dado ao processo coletivo ainda continua adstrito à concepção representativa, por não contemplar o cidadão como legitimado processual ativo para a sua propositura. A Constituição de 1988 reiterou o tratamento jurídico-legal dado a ação popular, como um instrumento hábil que legitima o cidadão no controle dos atos e das atividades estatais.

Pelo que fora exposto até o presente momento fica claramente demonstrada a exclusão do cidadão do rol dos legitimados ativos à propositura da ação civil pública no Brasil, fato esse que denota com clareza que se adota no ordenamento jurídico brasileiro o sistema representativo, ou seja, o legislador elegeu aleatoriamente algumas instituições 
pressupostamente legitimadas a gerir e reivindicar a proteção dos direitos metaindividuais, excluindo-se desse rol o cidadão. Ressalta-se, ainda, que a Lei 7347/85, que disciplina a ação civil pública no Brasil, não foi recepcionada pelo disposto no artigo $1^{\circ}$ da Constituição brasileira de 1988, que é categoria ao estabelecer expressamente a adoção do sistema participativo, fundamento constitucional expresso que confere ao cidadão o direito de ser reconhecido como legitimado processual ativo das ações coletivas, cujos efeitos jurídicos do provimento final atingem diretamente toda coletividade.

Importante esclarecer que um dos fundamentos da República Federativa do Brasil é a soberania popular e a cidadania, corolários constitucionais da legitimidade processual ativa do cidadão quanto à propositura da ação civil pública. É nesse contexto teórico-discursivo que será abordado na sequência o modelo constitucional de processo coletivo no Estado Democrático de Direito, considerado lócus de ampla e efetiva discursividade das questões processuais metaindividuais por todos os interessados difusos e coletivos.

\section{O modelo constitucional de processo no Estado Democrático de Direito}

As bases para a compreensão do Estado Democrático de Direito encontram-se na hermenêutica discursivo-constitucional, ou seja, na superação do personalismo hermenêutico, de interpretações meramente literais, gramaticais, históricas, teleológicas. Nesse sentido, a compreensão da sistematicidade jurídico-constitucional faz-se necessária na pós modernidade (LEAL, 2002, p. 30), para que as normas jurídicas sejam interpretadas a partir da Constituição. A jurisdição não pode mais ser estudada como o poder dever do Estado Juiz de dizer o direito no caso concreto, nem o processo ser visto como mero instrumento para o exercício da jurisdição (CINTRA; GRINOVER; DINAMARCO, 2005); a jurisdição dever ser compreendida como um direito fundamental e o processo como garantia constitucional (DIAS, 2004, p. 107-118). A superação do pessoalismo do julgador na análise do caso concreto é pressuposto teórico para o entendimento crítico-epistemológico de que o processo coletivo democrático é um espaço que legitima todos os interessados difusos e coletivos no debate amplo e constitucionalizado de todas as questões que integram a pretensão metaindividual deduzida em juízo.

A garantia de participação na construção do mérito do processo coletivo não deve ser uma prerrogativa adstrita ao personalismo do julgador, haja vista tratar-se de um direito 
fundamental garantidor da implementação da cidadania. O sistema representativo como parâmetro ao estudo do processo coletivo é a demonstração do caráter autocrático da legislação pátria, ao limitar o entendimento da legitimidade processual apenas àquelas pessoas autorizadas e escolhidas pelo legislador, como é o caso da exclusão do cidadão como legitimado para a propositura da ação civil pública.

A democracia é o regime político capaz de garantir formal e materialmente o exercício dos direitos fundamentais, cuja legitimidade perpassa pela participação dos seus destinatários na construção das normas jurídicas a partir da teoria do discurso jurídico, conforme entendimento preconizado por Habermas:

Neste ponto, é possível enfeixar as diferentes linhas de argumentação, a fim de fundamentar um sistema dos direitos que faça jus à autonomia privada e pública dos cidadãos. Esse sistema deve contemplar os direitos fundamentais que os cidadãos são obrigados a se atribuir mutuamente, caso queiram regular sua convivência com os meios legítimos do direito positivo (HABERMAS, 2003, p. 154).

Nesse mesmo sentido se manifesta Habermas: "A idéia da autolegislação de civis exige que os que estão submetidos ao direito, na qualidade de destinatários, possam entenderse também enquanto autores do direito" (HABERMAS, 2003, p. 157). O fundamento da legitimidade democrática é a garantia assegurada a todos os interessados de fiscalizar amplamente a construção participada do provimento. Nesse sentido ressalta-se o entendimento de Dhenis Cruz Madeira:

Por conseguinte, obstruir a fiscalidade popular sobre a norma jurídica é dar margem à vida nua, criando-se um espaço discursivo indemarcado e nãofiscalizável. Com isso, fomenta-se o aparecimento do espaço do soberano (e não o da soberania popular), do locutor autorizado da lei, que, à semelhança do soberano de Kafka, diz o que pode e o que não pode, sem, contudo, ofertar os fundamentos de suas decisões, ou mesmo, permitir que o destinatário da norma aponte as ausências do discurso normativo. Esse espaço do soberano, a nosso ver, permite a criação de uma dimensão política acima da jurídica (MADEIRA, 2008, p. 24).

Buscando-se os fundamentos teóricos precipuamente na doutrina da legitimação democrática do direito preconizada por Jürgen Habermas e na visão crítica falibilista (POPPER, 1987, p. 395-396) de Karl Popper, Rosemiro Leal se propõe a estudar o processo no Estado Democrático de Direito a partir da premissa de que não é uma simples espécie de procedimento, mas, sim, instituição constitucionalizada regente das estruturas procedimentais 


\section{PROCESSO COLETIVO DEMOCRÁTICO SOB A ÓTICA DA TEORIA DAS AÇÕES COLETIVAS COMO AÇÕES TEMÁTICAS: UM ESTUDO DA LEGITIMIDADE PROCESSUAL ATIVA DO CIDADÃO PROPOR AÇÃO CIVIL PÚBLICA}

preparatórias de provimentos estatais. Há uma identidade cientifica existente entre a teoria neo-institucionalista do processo e a teoria do modelo constitucional do processo, já que ambas buscam o seu fundamento teórico nos direitos fundamentais. Todavia, daquela teoria se afasta na medida em que coloca o processo como pressuposto de legitimidade "de toda criação, transformação, postulação e reconhecimento de direitos pelos provimentos legiferantes, judiciais e administrativos" (LEAL, 2000, p. 97).

Os direitos fundamentais, considerados o substrato interpretativo da presente teoria, serão enunciados jurídicos processualmente decididos por uma sociedade apta efetivamente ao exercício da cidadania. A pressuposição democrática é que o direito seja legitimamente projetado e construído por uma comunidade política consciente e conhecedora do projeto constitucional consistente na democratização da atividade legiferante (LEAL, 2004, p. 95-96). Nesse contexto propositivo, o exercício da cidadania no Estado Democrático de Direito pressupõe o conhecimento da teoria processual dos direitos fundamentais discursivamente construídos pelos seus destinatários. O referente lógico-jurídico para a compreensão da teoria neo-institucionalista do processo é a principiologia constitucional. Nos dizeres de Leal

\footnotetext{
De conseguinte, o que se busca com uma teoria neo-institucionalista do processo é a fixação constitucional do conceito do que seja juridicamente processo, tendo como base produtiva de seus conteúdos a estrutura de um Discurso advindo do exercício permanente da cidadania pela plebiscitariazação continuada no espaço processual das temáticas fundamentais à construção efetiva de uma Sociedade Jurídico-Política de Direito Democrático (LEAL, 2004, p. 97).
}

O processo deve buscar na hermenêutica constitucional democrática o referencial para a previsibilidade e objetividade das decisões judiciais. A qualidade democrática de uma sociedade jurídico-política é definida pela produção das normas jurídicas a partir da institucionalização do processo constitucional (LEAL, 2004, p. 98). O povo deve ser o pressuposto da legitimidade, criação, aplicação e alteração do direito.

O enunciado do processo para a teoria neo-institucionalista encontra-se nos princípios institutivos (LEAL, 2000, p. 103): contraditório, isonomia e ampla defesa. A marca fundamental do contraditório no paradigma do Estado Democrático é a igual oportunidade de participação dos interessados na construção dos provimentos estatais (LEAL, 2002). Para Dierle Nunes, o principio do contraditório é entendido tão somente como um direito de bilateralidade da audiência, possibilitando às partes a devida informação e possibilidade de 
reação (NUNES, 2004, p. 42). Gonçalves entende que o contraditório tem como base a liberdade na busca da decisão participada (GONÇALVES, 1992, p. 128). Através do contraditório, deve ser assegurada a defesa, não podendo ninguém ser condenado sem ela (CARREIRA ALVIM, 2004, p. 159).

É imprescindível a observância do contraditório pelo juiz, que deverá adotar as providências necessárias para assegurá-lo, para fazê-lo observar (ARAÚJO, 2003, p. 119). Trata-se de um direito-garantia das partes exercerem livremente o direito de nada dizerem (LEAL, 2004, p. 103). Propugna-se pela correlação existente entre o contraditório, a igualdade e o direito de ação. O exercício da função jurisdicional se dará com a obrigatória participação em contraditório dos interessados nos efeitos dos provimentos judiciais (DIAS, 2004, p. 87-88). Nesse contexto, observa-se que o principio do contraditório desencadeia uma serie de implicações na aquisição e na valoração da prova em vista da decisão sobre o fato (CATTONI DE OLIVEIRA, 2001, p. 160). Nesse sentido, destaca-se

Indispensável ao exercício do contraditório, a isonomia, enquanto direitogarantia constitucionalizada, preza pela liberdade de tratamento jurídico igual que não se opera pela distinção jurisdicional do economicamente igual ou desigual, ou seja, tal princípio constitucional não pode ser utilizado para conferir tratamento jurídico discriminatório aos indivíduos (LEAL, 2004, p. 103).

No âmbito do processo coletivo democrático, o contraditório efetiva-se com a oportunização conferida a todos os interessados difusos e coletivos de debater amplamente todos os pontos controversos da demanda no âmbito da constitucionalidade vigente. Ou seja, afastar o cidadão do rol dos legitimados e impedi-lo de participar processualmente do debate de todos os pontos controversos das demandas coletivas é a forma mais clara de deslegitimar democraticamente o provimento final.

Importante esclarecer que o grau de democraticidade do provimento final numa ação coletiva está diretamente vinculado à oportunidade efetiva conferida a todos os interessados difusos e coletivos de participarem discursivamente da construção do provimento final, algo que se torna inviável quando se compreende o processo coletivo na perspectiva do sistema representativo. A igualdade passa pelo exercício amplo, efetivo e irrestrito dos direitos fundamentais nos patamares constitucionais. A isonomia é o principio garantidor da igualdade argumentativa na formação do discurso de produção e aplicação do direito ao caso concreto. 
O princípio da isonomia é garantidor da igualdade procedimental de igual tratamento. O processo legitima o exercício da função jurisdicional por meio da isonomia processual. A isonomia processual, pressuposto do Estado Democrático, afasta qualquer tipo de privilegio e pró́be quaisquer distinções não autorizadas pelo texto constitucional. Nos dizeres de Leal, o Processo na Teoria do direito democrático é o ponto discursivo da igualdade dos diferentes (LEAL, 2004). No âmbito da processualidade democráticodiscursiva das ações coletivas a isonomia processual é pressuposto da legitimidade jurídica do provimento final, haja vista que a todos os interessados difusos e coletivos deverá ser oportunizado o direito de argumentar processualmente as questões controvertidas para, assim, participarem da construção do provimento final.

Considerada a co-extensão dos princípios do contraditório e da isonomia, a ampla defesa garante a irrestrita argumentação no direito de defesa. A dialeticidade entre as partes e a bilateralidade de ação são os elementos caracterizadores do contraditório, que deverá oportunizar o direito de informação e reação; o princípio da ampla defesa se materializa quer na defesa técnica exercida pelo advogado, quer na autodefesa do acusado (CINTRA; GRINOVER; DINAMARCO, 2005, p. 57-59).

Através do princípio da ampla defesa destaca-se que a todos os interessados difusos e coletivos deverá ser oportunizado o direito de produzir provas e esclarecer processualmente os pontos controversos e debatidos em juízo. Ou seja, além de oportunizar aos interessados difusos e coletivos o direito de produzir provas no âmbito das ações coletivas, sabe-se que a eles deverá ser assegurado o direito de ver tais provas juridicamente apreciadas de forma racional pelo julgador no ato de sua decisão.

A legitimidade democrática do provimento final nas ações coletivas está diretamente vinculada à oportunidade de argumentação ampla dos pontos controversos e produção de provas no âmbito processual, além da garantia conferida a todos os interessados de que seus argumentos e provas produzidos serão obrigatoriamente apreciados pelo magistrado em decisão jurídico-constitucionalmente fundamentada. Passaremos a seguir a discutir a problemática da reconstrução do processo coletivo a partir da teoria das ações coletivas como ações temáticas para, assim, compreender o modelo constitucional de processo no Estado Democrático de Direito.

\section{Teoria das ações coletivas como ações temáticas.}


A construção do mérito participado no processo coletivo pressupõe a ruptura com o entendimento do direito coletivo a partir do sistema representativo para, consequentemente, repensá-lo no modelo participativo. Por isso, é imperiosa a ampliação do rol de legitimados para, assim, permitir que o maior número possível de interessados possa defender suas teses em juízo. O processo coletivo no modelo constitucional democrático deve viabilizar amplamente o exercício da cidadania através da participação ampla e direta de todos os interessados na construção do mérito da demanda. Ou seja, o mérito da demanda não pode ser predefinido apenas pelos legitimados previamente determinados em lei, uma vez que a legitimidade democrática do provimento jurisdicional perpassará pela ampliação da participação de todos os legitimados e interessados na demanda: "Quanto maior fosse a participação na formação do mérito, maior seria a legitimação da decisão do processo coletivo em relação aos efeitos que produziria em face dos interessados difusos" (MACIEL JUNIOR, 2006, p. 181). É nesse contexto que se constrói a teoria das ações coletivas como ações temáticas:

\begin{abstract}
A ação coletiva dever ser a demanda que propõe um tema, abrindo a possibilidade de que o próprio conteúdo do processo seja definido de modo participativo. $\mathrm{O}$ processo coletivo demanda, portanto, uma fase inicial na qual o seu objeto seja formado. O mérito do processo é construído, dentro de um determinado período de tempo fixado na lei, até quando será possível que os diversos interessados compareçam na demanda e formulem seus pedidos (MACIEL JUNIOR, 2006, p. 179).
\end{abstract}

A formação participada do mérito no processo coletivo não se dará no momento inicial de propositura da ação, mas sim será construído mediante a oportunização efetiva de todos os interessados difusos juridicamente legitimados apresentarem temas coerentes com a pretensão inicialmente deduzida em juízo para, a partir desse contexto, reconstruir o processo coletivo democrático a partir do sistema participativo. "A criação de um procedimento específico para as ações temáticas é algo indispensável na conjuntura da construção participada do mérito processual e, especialmente, no estabelecimento dos limites da demanda" (COSTA, 2012, p. 230).

O momento processual para a estabilização da demanda dar-se-á através da fixação dos pontos controvertidos, que será após a efetivação do direito de participação em contraditório no processo decisório que afetará todos os interessados. A realização de audiências públicas para o debate de questões transindividuais objeto de ações coletivas é 


\section{PROCESSO COLETIVO DEMOCRÁTICO SOB A ÓTICA DA TEORIA DAS AÇÕES COLETIVAS COMO AÇÕES TEMÁTICAS: UM ESTUDO DA LEGITIMIDADE PROCESSUAL ATIVA DO CIDADÃO PROPOR AÇÃO CIVIL PÚBLICA}

imprescindível na delimitação e debate amplo dos pontos controversos da demanda por todos os interessados difusos. No âmbito do processo coletivo democrático verifica-se que toda coletividade é diretamente atingida pelos efeitos jurídicos do provimento final, razão essa que legitima sua participação discursiva na definição e debate amplo dos pontos controvertidos.

A implementação do contraditório, enquanto princípio institutivo do processo (LEAL, 2000) dar-se-á através da efetiva participação de todos os interessados difusos na construção do mérito do processo coletivo e, conseqüentemente, na construção participada do provimento jurisdicional. Trata-se de uma teoria cujo conceito de jurisdição não se encontra centrado solitariamente na pessoa do julgador que, mediante a efetiva participação na construção do mérito, terá reais condições de proferir sua decisão, vinculando-se a todos os pontos controversos debatidos e todas as provas produzidas processualmente pelas partes interessadas. Ou seja, constitui dever do magistrado fundamentar jurídico-constitucionalmente sua decisão a partir de tudo que foi debatido e provado pelos interessados difusos e coletivos no âmbito processual.

Serão considerados legitimados à construção do mérito do processo coletivo todos aqueles interessados que demonstrarem que sofrerão os efeitos da decisão judicial. Nesse sentido temos:

\footnotetext{
Proposta uma ação cuja decisão envolva bem que afete um numero indeterminado de pessoas, o ideal seria que a lei fixasse uma fase de divulgação para que os interessados difusos tomassem ciência e pudessem intervir no processo. Nas ações coletivas poderia ser estabelecida a obrigatória participação do Ministério Publico, o que já ampliaria o rol dos legitimados presentes na ação e envolverá um órgão que tem por função primordial a defesa da legalidade.

Recebida a defesa e os eventuais aditamentos à inicial, deveria haver um despacho saneador no qual o juiz obrigatoriamente fixasse os pontos controvertidos e o objeto da prova e resolvesse as demais questões do processo (MACIEL JUNIOR, 2006, p. 183).
}

Admitir o Ministério Público como o legitimado exclusivo e principal à propositura das ações coletivas é legitimar a violação do princípio do contraditório e ampla defesa, em razão da impossibilidade de participação de todos os interessados difusos na construção participada do mérito coletivo, pois dessa forma suprime-se o direito de debate amplo dos pontos controversos e das provas processualmente produzidas pelas partes interessadas. A publicização da pretensão deduzida é o fundamento para a construção participada do mérito, mediante ampla fiscalidade por todos aqueles juridicamente interessados. 


\subsection{A construção do mérito processual pelo sistema participativo}

A compreensão critica do mérito participado perpassa pelo entendimento do processo e das ações coletivas sob a ótica do processo constitucional no Estado Democrático de Direito. Toda problemática proposta passa inicialmente pela distinção jus-filosófica existente entre direito e interesse.

Inicialmente é importante ressaltar o pensamento de Ihering, considerado um utilitarista, que compreendia o direito a partir da idéia de existência de um fim prático. É como explicita Vicente de Paula Maciel Junior, citando Edgard Bodenheimer "Ihering calcou o ponto centrar de sua Filosofia do Direito no fim. O fim como criador de todo o Direito, não havendo norma jurídica que não deva sua origem a um fim ou motivo prático" (MACIEL JUNIOR, 2006, p. 20). È nesse contexto que Vicente de Paula Maciel Junior afirma que "Ihering entendia que os direitos não existem apenas para realizar a idéia de vontade jurídica abstrata" (MACIEL JUNIOR, 2006, p. 20). Dessa forma, sabe-se que para Ihering os direitos são vistos como interesses juridicamente protegidos.

A compreensão de direito a partir da obra de Ihering é se dá em bases propostas pelo liberalismo, baseando-se na premissa de direitos individuais. Além disso, não se pode pensar o direito enquanto ciência sob a ótica processual, uma vez que os fundamentos metajuridicos e de cunho axiológico representam o norte de toda a obra de Ihering. Dessa forma é possível afirmar que atualmente a inaplicabilidade da Teoria de Ihering evidencia-se na necessidade de proteção jurídica não apenas de direitos individuais e de relações jurídicas e privadas construídas entre particulares, mas, acima de tudo, no interesse em proteger direitos coletivos, cuja titularidade é da coletividade, e não apenas de um individuo em si.

A partir das considerações iniciais apresentadas, afirma-se que os interesses jurídicos são construções individuais e de caráter liberal, cuja aplicabilidade no âmbito coletivo tornase inviável. Dessa forma, sabe-se que juridicamente o mais adequado não é falar em interesses metaindividuais ou transindividuais, conforme preconiza alguns autores, mas sim em direitos coletivos, cuja efetivação dar-se-á através das ações coletivas e do processo coletivo. Nesse sentido revela-se o entendimento do professor Vicente de Paula Maciel Junior:

Negamos em diversas oportunidades em nossa exposição a existência de interesses coletivos e difusos. Sob o nosso prisma, os interesses são sempre individuais e, se assim é, não há como reconhecer que a manifestação

Rev. de Processo, Jurisdição e Efetividade da Justiça | e-ISSN: 2525-9814 | Porto Alegre | v. 4 | n. 2 | p. $01-22$ | Jul/Dez. 2018 


\section{PROCESSO COLETIVO DEMOCRÁTICO SOB A ÓTICA DA TEORIA DAS AÇÕES COLETIVAS COMO AÇÕES TEMÁTICAS: UM ESTUDO DA LEGITIMIDADE PROCESSUAL ATIVA DO CIDADÃO PROPOR AÇÃO CIVIL PÚBLICA}

individual do interesse de uma parte em face de um bem possa ser difusa. $\mathrm{O}$ interesse é sempre identificável e relacionado a uma pessoa que manifesta sua intenção. Até mesmo a difundida expressão interesses difusos foi idealizada tomando como pressuposto básico os sujeitos, para ressaltar que, com relação a essa espécie de interesses não há como identificar cada um daqueles possíveis interessados (MACIEL JUNIOR, 2006, p. 57-58).

A garantia efetiva da participação pressupõe a publicização e a divulgação ampla da pretensão através de editais e outros meios de comunicação efetivos, tais como os veículos de comunicação, para que todos aqueles juridicamente interessados tenham a oportunidade de participação das discussões jurídico-constitucionais da pretensão metaindividual. Essa foi a proposta adotada pela nova Lei de Ação Civil Publica em seu artigo 13, que consagra no plano infraconstitucional o direito de todos os interessados difusos e coletivos de participarem o debate processual da demanda transindividual, cujos efeitos jurídicos do provimento final atingirão a todos os interessados.

Importante esclarecer nessa publicização o objeto exato a ser discutido, com o propósito de impedir alegações e discussões impertinentes e não relacionadas com a pretensão inicialmente deduzida. O controle dessa participação mediante a apresentação dos temas suscitados pelas partes interessadas será feito democraticamente pelo Ministério Publico e pelo magistrado, priorizando-se, sempre que possível, o debate que venha acrescentar, enriquecer e contribuir para o julgamento da lide.

Imagine, por exemplo, uma ação civil publica cuja pretensão é a extinção de festas populares na cidade de Ouro Preto, visando a proteção do patrimônio histórico-cultural, que é patrimônio da humanidade. Certamente o judiciário deverá se incumbir de divulgar amplamente o objeto da presente ação coletiva, para oportunizar efetivamente a participação de todos aqueles interessados na proteção do patrimônio histórico-cultural da cidade de Ouro Preto. Tal participação não será assegurada apenas aos cidadãos de Ouro Preto nem de Minas Gerais, tendo em vista a existência de sujeitos indiretamente interessados no objeto da presente ação coletiva.

Talvez o grande desafio prático enfrentado pelo Judiciário seja instrumentalizar efetivamente tal participação, argumento esse que deve ser rechaçado e que não pode ser utilizado como subterfúgio à supressão da construção participada do mérito participado das ações coletivas. Considerando que tal participação é um direito fundamental assegurado a todos os cidadãos juridicamente interessados e atingidos pelos efeitos do provimento 
jurisdicional, afirma-se que problemas estruturais enfrentados pelo judiciário jamais poderão ser argumentos utilizados para suprimir tal participação.

Ressalta-se, ainda, a obrigatoriedade de observância efetiva dos princípios constitucionais da isonomia processual, contraditório e ampla defesa, para que não haja participações meramente formais na discussão do mérito das ações coletivas. No momento da construção do provimento jurisdicional o magistrado deverá apresentar argumentos jurídicos suficientes para admitir ou rechaçar as alegações apresentadas por todos aqueles que participaram do debate jurídico da pretensão coletiva.

É importante que fique claro que o foco de discussão para a construção participada do mérito na teoria das ações coletivas como ações temáticas é o objeto, e não o sujeito, uma vez que a legitimidade democrática do provimento jurisdicional não se limita em oportunizar a todos os cidadãos o direito de participar diretamente da construção do provimento, mas sim oportunizar, mediante o principio da publicidade, que sejam apresentados todos os temas e argumentos possíveis, coerentes e pertinentes com a pretensão inicialmente deduzida. È nesse sentido que o mérito participado deve ser pensado: garantir efetivamente a oportunidade de apresentação de todos os temas, argumentos e alegações pertinentes a pretensão coletiva ou difusa inicialmente deduzida em juízo, como forma de definir o objeto do processo coletivo e conseqüentemente viabilizar a construção participada do mérito.

\section{Legitimidade processual ativa do cidadão propor ação civil pública e participar discursivamente da construção do mérito processual}

A compreensão do processo coletivo democrático, na perspectiva constitucional, condiciona-se à desconstrução do sistema representativo, com o advento do sistema participativo, parâmetro indispensável à garantia da legitimidade democrática de ampla argumentação e construção discursiva do mérito processual e provimento final por todos os interessados difusos e coletivos. O princípio democrático deve "permitir aos cidadãos o seu desenvolvimento, mediante a liberdade de participação nos processos políticos, econômicos e sociais em consonância com o estabelecimento de uma sociedade livre, justa e solidária segundo ditames da constituição" (FERREIRA, 2016, p. 36). Dessa forma, "o sistema representativo deve ser suplantado em prol de um sistema participativo", pois será somente mediante o resgate da participação popular que se torna juridicamente viável a interferência procedimental do cidadão, com a consequente "legitimidade das decisões e da construção da 
ciência processual sob o prisma do Estado Democrático de Direito" (FERREIRA, 2016, p. 167-168).

"A ativação do povo ocorre com o reconhecimento aos cidadãos da prerrogativa de veicular pretensões fundamentadas que vinculem a produção de decisões públicas, especialmente no que concerne ao gozo de direitos fundamentais (autoinclusão) (GRESTA, 2014, p. 57). "É a partir do conceito de procedimento que se extrai um novo conceito de processo", haja vista que "Elio Fazzalari inclui o processo na classe do procedimento, caracterizando-o pelo elemento do contraditório, entendido como a possibilidade de os destinatários do provimento participarem de forma simétrica na construção deste, seja ele final ou interlocutório" (PINHEIRO, 2016, p. 194).

O artigo 5., da Lei 7347/85, estabelece expressamente um rol taxativo de legitimados ativos à propositura da ação civil pública: Ministério Público; defensoria pública; união, estados, distrito federal e municípios; autarquias, empresas públicas, fundações e sociedade de economia mista; associações constituídas há pelo menos um ano, que inclua entre suas finalidades institucionais a proteção de direitos coletivos ou difusos. $O$ cidadão individualmente foi excluído do referido rol de legitimados ativos, embora sofra diretamente os efeitos jurídicos do provimento final.

Em razão disso, fica evidente que a lei de ação civil pública adotou como critério regente de sua sistematização teórica o sistema representativo, motivo esse que explicita sua não recepção pelo texto da constituição brasileira de 1988. No momento em que a referida lei afastou o cidadão do rol dos legitimados ativos, deixou de adotar o sistema participativo e, por conseguinte, inobservou o modelo constitucional de processo. O cidadão, embora sofra todos os efeitos jurídicos do provimento final, fica impossibilitado de integrar o espaço processual de ampla dialeticidade dos pontos controversos que integram a demanda metaindividual.

Tal fato é explicado porque "a base de todo o processo coletivo brasileiro vigente encontra-se no sistema representativo. Trata-se de modelo de processo através do qual o legislador, solitária e unilateralmente, é quem define os legitimados à propositura de uma ação coletiva" (COSTA, 2012, p. 129). A adoção desse modelo autocrático de processo coletivo pelo direito brasileiro fortalece a discricionariedade judicial, robustecendo o exercício unilateral e solipsista da atividade jurisdicional pelo magistrado. "O drama da discricionariedade que critico reside no fato de que esta transforma os juízes em legisladores", 
ressaltando-se que "esse poder discricionário propicia a criação do próprio objeto do conhecimento, típica manifestação do positivismo" (STRECK, 2012, p. 93).

"No âmbito da processualidade democrática o magistrado não pode se utilizar de argumentos metajurídicos (axiologizantes) como justificativa para inviabilizar o exercício ou retirar a titularidade dos direitos fundamentais previamente definidos no plano constituinte" (COSTA, 2016, p. 192). Sempre que o legislador ou o magistrado se utiliza de técnicas procedimentais para limitar o espaço processual de discursividade da pretensão deduzida contraria o modelo de processo constitucional democrático. No momento em que a lei de ação civil pública impede expressamente o direito de o cidadão propor a referida ação coletiva, deixa de adotar o sistema participativo, expressamente previsto no plano constitucional, além de limitar o espaço de argumentação jurídica dos pontos controversos e formação participada do mérito processual.

“O processo constitucional eleva o processo à instituição constitucionalizada orientada pelos direitos e garantias fundamentais, cuja viga-mestra é o devido processo constitucional, que é o espaço normativo (locus de discursividade)", pois é "onde será possível a ampla defesa realmente ampla e plenária pela, pela exauriência argumentativa" (CRUZ, 2016, p. 66).

Ressignificar teoricamente a forma de compreender o processo coletivo no Estado Democrático de Direito constitui um meio de adequá-lo ao sistema participativo. Dessa forma, a legitimidade de os interessados participarem da formação do mérito processual deverá decorrer da pretensão inicialmente deduzida em juízo. Não será o legislador quem terá legitimidade jurídica de definir aprioristicamente os legitimados ativos à ação civil pública. Pelo contrário, com fundamento na teoria das ações coletivas como ações temáticas, a partir do objeto da ação coletiva é que será possível dimensionar os sujeitos afetados juridicamente pelos efeitos do provimento final. Após essa análise feita pelo magistrado, deve-se instituir procedimento legal de ampliação do espaço processual de debate, privilegiando a exauriência argumentativa como meio de assegurar a legitimidade democrática do conteúdo decisório.

\section{Conclusão}

A reconstrução do processo coletivo a partir do modelo constitucional de processo passa pelo entendimento da teoria das ações coletivas como ações temáticas, que utiliza o sistema participativo como instrumento de ampla fiscalidade a ser exercida pelo cidadão, 
focando todo seu debate não no sujeito, mas sim no objeto. Dessa forma, o rol de legitimados ativos à propositura da ação civil pública não pode ser taxativo e deve contemplar amplamente todo aquele que demonstrar interesse jurídico na pretensão deduzida em juízo, ou seja, todo interessado difuso ou coletivo afetado pelos efeitos jurídicos do provimento final tem legitimidade democrática de participar do debate dos pontos controversos e da produção de provas no âmbito processual.

É nesse contexto da reflexão cientifica que o presente debate ressalta a necessidade de implementação da disciplina de teoria geral do processo coletivo como forma de superação do entendimento individualista e autocrático no estudo do processo coletivo vigente, proposto pela Escola Instrumentalista. Manter a compreensão do processo coletivo a partir de concepções liberais e individualistas é legitimar o sistema representativo e, assim, afastar os interessados difusos e coletivos da construção discursiva do provimento final das ações civis públicas.

Nesse ínterim é oportuna a necessidade de sistematização de toda a legislação pertinente ao direito e ao processo coletivo democrático, para que se obtenha a autonomia cientifica necessária ao reconhecimento de tal disciplina. A existência de legislações esparsas centradas ainda no sistema representativo certamente compromete a identidade do tema em questão.

A regulamentação da procedimentalização do processo coletivo democrático é considerada matéria urgente, tendo em vista a finalidade de esclarecer como se efetiva a possibilidade de participação e de exercício do contraditório e da ampla defesa por todos aqueles juridicamente interessados. É de suma importância, ainda, a delimitação do momento processual da estabilização da pretensão deduzida e até qual fase do procedimento será possível a intervenção de terceiros para construir discursivamente o mérito processual coletivo. Outra questão que merece destaque diz respeito aos reflexos da estabilização da demanda na constituição da coisa julgadas e de seus efeitos legais, que não integrou especificamente o objeto da presente pesquisa.

A democraticidade na formação do mérito processual nas ações civis públicas decorre da legítima oportunidade de participação de todos os sujeitos interessados na formação discursiva do provimento final. Considerando-se os direitos difusos e coletivos, sabe-se que a garantia da legitimidade democrática do provimento jurisdicional passa 
diretamente pela oportunidade efetiva conferida aos interessados difusos e coletivos de definirem os pontos controversos da demanda, debaterem e produzirem provas no sentido de esclarecê-los. Ao magistrado incumbe o dever de manifestar-se de forma jurídicoconstitucionalmente fundamentada sobre todos os pontos controversos debatidos e todas as provas produzidas pelas partes interessadas.

Limitar ou restringir a participação dos interessados difusos na construção do provimento final de uma ação civil pública é legitimar um modelo autocrático de processo ainda pautado na autoridade pressuposta do magistrado mediante decisões solitárias e solipsistas. O modelo constitucional de processo coletivo no Estado Democrático materializa a oportunidade de os destinatários do provimento final serem seus co-autores.

A lei da ação civil pública, especificamente no ponto em que estabelece o rol taxativo dos seus legitimados ativos, excluindo-se o cidadão, é considerada materialmente não recepcionada pelo texto constitucional, pois ofende o sistema participativo, que no artigo 1 ., da constituição brasileira de 1988, autoriza todos os interessados difusos e coletivos participarem dialogicamente da formação participada do mérito processual. Pensar o processo coletivo a partir do objeto, não mais sob a ótica do sujeito, é um meio de superar os juízos apriorísticos impostos pelo legislador quando previu o referido rol taxativo. A partir do objeto da ação civil pública proposta, o magistrado verificará quais são os sujeitos potencialmente atingidos pelo provimento final e, assim, assegurará o direito de todos, indistintamente, participarem democraticamente da construção do conteúdo decisório.

\section{Referências}

AGUIAR, Cynara Silde Mesquita Veloso de; COSTA, Fabrício Veiga; SOUZA, Maria Inês Rodrigues de et al. Processo, Ação e Jurisdição em Oskar von Bülow. Estudos Continuados de Teoria do Processo. Coordenador: Rosemiro Pereira Leal. v. VI. Porto Alegre: Síntese, 2005.

ALMEIDA, Gregório Assagra de. Codificação do Direito Processual Coletivo brasileiro. Belo Horizonte: Del Rey, 2007.

ARAÚJO, Marcelo Cunha. O Novo Processo Constitucional.Belo Horizonte: Mandamentos, 2003.

BRASIL. Vademecum. 3. ed. São Paulo: Saraiva, 2007.

BRASIL. Constituições Brasileiras. v. 3. Brasília: Senado Federal e Ministério da Ciência e 
Tecnologia, Centro de Estudos Estratégicos, 2001.

BRASIL. Constituições Brasileiras. v. 5. Brasília: Senado Federal e Ministério da Ciência e

Tecnologia, Centro de Estudos Estratégicos, 2001.

BRASIL. Constituições Brasileiras. v. 6. Brasília: Senado Federal e Ministério da Ciência e Tecnologia, Centro de Estudos Estratégicos, 2001.

CARREIRA ALVIM, José Eduardo. Elementos de Teoria Geral do Processo. Rio de Janeiro: Forense, 2004.

CATTONI DE OLIVEIRA, Marcelo Andrade. Direito Processual Constitucional. Belo Horizonte:Mandamentos, 2001.

CINTRA, Antônio Carlos de Araújo; GRINOVER, Ada Pelegrini; DINAMARCO, Cândido Rangel. Teoria Geral do Processo. 21 ed. São Paulo: Malheiros, 2005.

COSTA, Beatriz Souza. Meio ambiente como direito à vida: Brasil, Portugal, Espanha. 1. ed. Belo Horizonte: Editora O Lutador, 2010.

COSTA, Fabrício Veiga. MÉRITO PROCESSUAL - a formação participada nas ações coletivas. Belo Horizonte: Arraes, 2012.

COSTA, Fabrício Veiga. LIQUIDEZ E CERTEZA DOS DIREITOS FUNDAMENTAIS NO PROCESSO CONSTITUCIONAL DEMOCRÁTICO. Rio de Janeiro: Lumen Juris, 2016.

CRUZ, Clenderson. A AMPLA DEFESA NA PROCESSUALIDADE DEMOCRÁTICA. Rio de Janeiro: Lumen Juris, 2016.

DIAS,Ronaldo Bretas de Carvalho. Responsabilidade do Estado pela Função Jurisdicional. Belo Horizonte: Del Rey, 2004.

FERREIRA, Juliana Maria Matos. TEORIA DO PROCESSO COLETIVO NO MODELO PARTICIPATIVO. Belo Horizonte: D’Plácido, 2016.

GONÇALVES, Aroldo Plinio. Técnica Processual e Teoria do Processo. Rio de Janeiro: Aide, 1992.

GALUPPO, Marcelo Campos. Igualdade e Diferença - Estado Democrático de Direito a partir do pensamento de Habermas. Belo Horizonte: Mandamentos, 2002.

GRESTA, Roberta Maia. INTRODUÇÃO AOS FUNDAMENTOS DA PROCESSUALIDADE DEMOCRÁTICA. Rio de Janeiro: Lumen Juris, 2014.

HABERMAS, Jürgen. DIREITO E DEMOCRACIA entre faticidade e validade. 2. ed. v. I. Rio de Janeiro: Tempo Brasileiro, 2003.

Rev. de Processo, Jurisdição e Efetividade da Justiça | e-ISSN: 2525-9814 | Porto Alegre | v. 4 | n. 2 | p. $01-22$ | Jul/Dez. 2018 
LEAL, André Cordeiro. Instrumentalidade do Processo em Crise. Belo Horizonte:

Mandamentos, 2008.

LEAL, Rosemiro Pereira. Teoria Processual da Decisão Jurídica. São Paulo: Landy, 2002.

LEAL, Rosemiro Pereira. Teoria Geral do Processo Primeiros Estudos. 5. ed. São Paulo:

Thomson-IOB, 2004.

LEAL, Rosemiro Pereira. Relativização Inconstitucional da Coisa Julgada - Temática

Processual e Reflexões Jurídicas.Belo Horizonte: Del Rey, 2005.

LEONEL, Ricardo de Barros. Manual do Processo Coletivo de acordo com a Lei 10.444/02.

São Paulo: Revista dos Tribunais, 2002.

MACIEL JUNIOR, Vicente de Paula. Teoria das Ações Coletivas - As ações coletivas como ações temáticas. São Paulo: LTr, 2006.

MADEIRA, Dhenis Cruz. Processo de conhecimento e cognição - uma inserção no Estado

Democrático de Direito. Curitiba: Juruá, 2008.

PINHEIRO, Guilherme César. A VINCULAÇÃO DECISÓRIA NO ESTADO DEMOCRÁTICO

DE DIREITO - por uma compreensão constitucionalmente adequada da aplicação de precedentes, súmulas e decisões vinculantes. Rio de Janeiro: Lumen Juris, 2016.

POPPER, Karl R. A Sociedade Aberta e seus Inimigos. Trad. Milton Amado. Belo Horizonte:

Itatiaia - EDUSP, 1987, v. 2.

RODRIGUES, Marcelo Abelha. Direito ambiental esquematizado. 1 ed. São Paulo: Editora Saraiva, 2013.

SILVA, Vasco Pereira da. Verdes são também os direitos do homem: responsabilidade administrativa em matéria de ambiente. Cascais: Principia, 2000.

STRECK, Lenio Luiz. O QUE É ISTO - DECIDO CONFORME MINHA CONSCIÊNCIA?

Porto Alegre: Livraria do Advogado, 2012. 